\title{
openheart Echocardiography during submaximal isometric exercise in children with repaired coarctation of the aorta compared with controls
}

Joseph Panzer (D) , Laure Dequeker, Ilse Coomans, Kristof Vandekerckhove, Thierry Bove, Daniël De Wolf, Ernst Rietzschel

To cite: Panzer J, Dequeker L, Coomans I, et al. Echocardiography during submaximal isometric exercise in children with repaired coarctation of the aorta compared with controls. Open Heart 2019;6:e001075. doi:10.1136/ openhrt-2019-001075

Received 26 April 2019 Revised 5 July 2019 Accepted 12 September 2019

Check for updates

(c) Author(s) (or their employer(s)) 2019. Re-use permitted under CC BY-NC. No commercial re-use. See rights and permissions. Published by BMJ.

Pediatric Cardiology and Cardiac Surgery Department, UZ Gent, Gent, Belgium

Correspondence to Dr Joseph Panzer; Joseph. Panzer@UZGent.be

\section{ABSTRACT}

Objective Patients with repaired coarctation ( $\mathrm{RCOA})$ remain at higher risk of cardiac dysfunction, initially often only detected during exercise. In this study, haemodynamics of isometric handgrip $(\mathrm{HG})$ and bicycle ergometry (BE) were compared in patients with RCoA and matched controls (MCs).

Methods Case-control study of 19 children with RCoA (mean age $12.9 \pm 2.3$ years; mean age of repair 7 months) compared with $20 \mathrm{MC}$. HG with echocardiography followed by $\mathrm{BE}$ was performed in both groups.

Results During HG (blood pressure) BP increased from $114 \pm 11 / 64 \pm 4 \mathrm{~mm} \mathrm{Hg}$ to $132 \pm 14 / 79 \pm 7 \mathrm{~mm} \mathrm{Hg}$, without significant differences. During $H G$ as well as $B E, H R$ increased less in patients with $\mathrm{RCOA}$. There were no significant differences in (left ventricle) LV dimensions or LV mass.

The RCoA group had diastolic dysfunction: both at rest and during $H G$ they had significantly higher transmitral $E$ and $A$ velocities and lower tissue Doppler $E^{\prime}$ and $A^{\prime}$ velocities. $E / E^{\prime}$ was higher, reaching statistical significance during $H G$ $(p<0001)$.

Conventional parameters of systolic function (FS and $\mathrm{EF}$ ) were similar at rest and HG. More sensitive tissue Doppler $\mathrm{S}^{\prime}$ was significantly lower at rest in CoA subjects $(5.1 \pm 1.5$ $\mathrm{cm} / \mathrm{s}$ vs $6.5 \pm 1 \pm 1 \mathrm{~cm} / \mathrm{s} ; \mathrm{p}<0.01)$, decreasing further during $\mathrm{HG}$ by $5 \%$ in the $\mathrm{COA}$ group (NS) while unchanged in controls.

Conclusions We provide first evidence that $\mathrm{HG}$ with echocardiography is feasible, easy and patient-friendly. A decreased systolic (tissue Doppler) and impaired diastolic LV function was measured in the RCoA group, a difference that tended to increase during $\mathrm{HG}$.

\section{INTRODUCTION}

Coarctation of the aorta (CoA) is a type of congenital heart disease characterised by stenosis in the aorta, typically juxta-ductal. The incidence is 1 in 2000 live births, ${ }^{1-3}$ representing $5 \%-8 \%$ of the congenital cardiovascular malformations. ${ }^{1-6}$ It can occur with other congenital lesions, most commonly bicuspid aortic valve (BAV) and ventricular septum defect. ${ }^{23}$

\section{Key questions}

What is already known about this subject?

- Haemodynamics as measured by echocardiography (and blood pressure) during isometric exercise have been studied in adults but not in children with repaired coarctation of the aorta.

- We know that cardiac problems and hypertension occur frequently after successful repair of coarctation. Initially, cardiac dysfunction may only be present during exercise.

What does this study add?

- Our study shows that it is feasible and easy to do echocardiography during a child-friendly stress-test

- We show that a decreased systolic and diastolic function is present in the repaired coarctation group and tended to increase during handgrip test.

How might this impact on clinical practice?

- We believe that echocardiography during isometric exercise is feasible and easy and adds to the haemodynamic understanding of patients with repaired coarctation. Future studies will hopefully elucidate where this technique has added value in routine follow-up.

Severe CoA results in hypertension proximal to the stenosis and leads to significant pressure differences between the right arm and leg. ${ }^{1367}$

Treatment of CoA consists of surgical resection of the narrowing or balloon dilatation with or without stenting. ${ }^{26}$ Even after successful repair, considerable morbidity and increased mortality remains in these patients and is related to complications like recoarctation, aortic aneurysm or dissection, premature coronary atherosclerosis, coexisting BAV and endocarditis. ${ }^{8}{ }^{1} 5^{9-11}$ Hypertension is the most important determinant for adverse outcomes. $^{12}$

Many recent studies have shown that the precoarctation vascular wall is 
abnormal. $^{5}$ 9 12-16 $^{16}$ This results in vascular and ventricular abnormalities in coarctation patients, especially after late repair. ${ }^{9101617}$ Early repair of the aortic obstruction cannot change the intrinsic structural abnormalities of the aortic wall. ${ }^{39121316}$ CoA should be considered a complex cardiovascular syndrome rather than an isolated stricture. ${ }^{79} 1017$

Exercise-induced hypertension is common in these patients and is assumed to be a predictor of arterial hypertension. ${ }^{18} 121920$

Pharmacological stress testing (eg, dobutamine) is generally used when exercise testing is not possible or when additional tests have to be performed, like echocardiography. Being invasive, it is not ideal in children. ${ }^{21}$

Currently, routine follow-up in most centres includes blood pressure measurements and bicycle exercise testing, as well as echocardiography (at rest but not during exercise). ${ }^{3} 1022$

Isometric handgrip test is a sustained submaximal stress test. ${ }^{23}$ The fact that this test causes limited movement of the body implies that a simultaneous echocardiography is possible. ${ }^{24}$ The complementary use of echocardiography during exercise may aid in the early detection of abnormalities in patients with a repaired coarctation. ${ }^{1525}$

\section{STUDY OBJECTIVES}

In this study, the effect of isometric exercise on the cardiovascular system of patients with a successfully repaired $\mathrm{CoA}$ is investigated. To enhance our understanding of haemodynamic changes in these patients, sustained submaximal isometric exercise and maximal dynamic exercise were executed. We performed an explorative investigation with prospective evaluation of 19 patients with isolated coarctation who underwent surgery at Ghent University Hospital and compared their results with healthy matched controls.

The aims of this study are: (1) to compare blood pressure and cardiac ultrasound measurements during isometric exercise of patients with a repaired coarctation with healthy controls and (2) to compare blood pressure during isometric exercise with blood pressure during dynamic exercise in children with a repaired CoA and healthy controls.

\section{METHODS}

This study was designed as a case-control study where patients with repaired coarctation are compared with age-matched and sex-matched controls.

Patients with coarctation were identified from Ghent University Hospital's database. Inclusion criteria for this database were: patients aged 9-16 years with CoA repaired with end-to-end anastomosis at this institute. This resulted in a group of 113 patients. We studied CoA patients who were operated without: (1) major associated cardiovascular abnormalities, (2) evidence of recoarctation (limit was set up at $>20 \mathrm{~mm} \mathrm{Hg}$ pressure gradient in the aortic arch by echocardiography) and (3) other serious concomitant disorders (one patient was excluded due to a syndrome affecting multiple organs). This left 39 patients suitable subjects. Nineteen children agreed to participate in this prospective study (figure 2). All patients were clinically well and taking no medication.

Twenty healthy normotensive children of similar age and matched for weight, height and sex served as control subjects. They were recruited by poster recruitment from local schools.

All subjects and their parents gave written informed consent.

\section{Exercise testing}

Each study started by obtaining blood pressure and heart rate (HR) at rest. The first exercise test performed by every participant was isometric handgrip. After a period of rest $(30 \mathrm{~min})$, patients underwent bicycle ergometry until exhaustion.

\section{Baseline data}

Demographic data, including, age, interventions and associated diseases were extracted from medical records. Height and weight were measured. Blood pressure and HR were obtained at rest, during isometric exercise and during bicycle exercise testing. Blood pressure was measured in the supine position with the cuff positioned on the right arm (to avoid operation-related disturbances) using an automatic blood pressure monitor (Spot Vital Signs LXi, Welch Allyn, Skaneateles Falls, USA). Average was taken from at least two separate readings.

\section{Isometric handgrip}

A handgrip dynamometer (Biometrics G200/H500 Modified Jamar Dynanometer) connected to an X4-InterX interface (Biometrics Ltd, GWENT, UK) was held in the left hand while lying on a hospital bed. First, the participant performed three efforts of maximum grip strength with the highest noted as maximum voluntary contraction (MVC). Then the subject was asked to sustain isometric exercise at $25 \%$ of MCV with the same instrument. A display of a seesaw was positioned at eye level to provide visual feedback. In that way the participants and observer knew if enough grip strength was provided. During exercise, they were watched carefully to avoid a Valsalva manoeuvre.

Participants were instructed to state when they thought that they would only be able to sustain the exercise for a further $60 \mathrm{~s}$. At this point, blood pressure and echocardiography were performed. To compare these measurements with values at rest, blood pressure and echocardiography were noted before and after exercise.

Echocardiography was performed with a Vivid 7 ultrasound imaging system, using a 3S transthoracic probe (GE Healthcare, Norway).

All echocardiographic examinations were performed by the same experienced paediatric cardiologist. The echocardiographic analyses were done with EchoPAC software (GE Healthcare) by another blinded investigator. In 


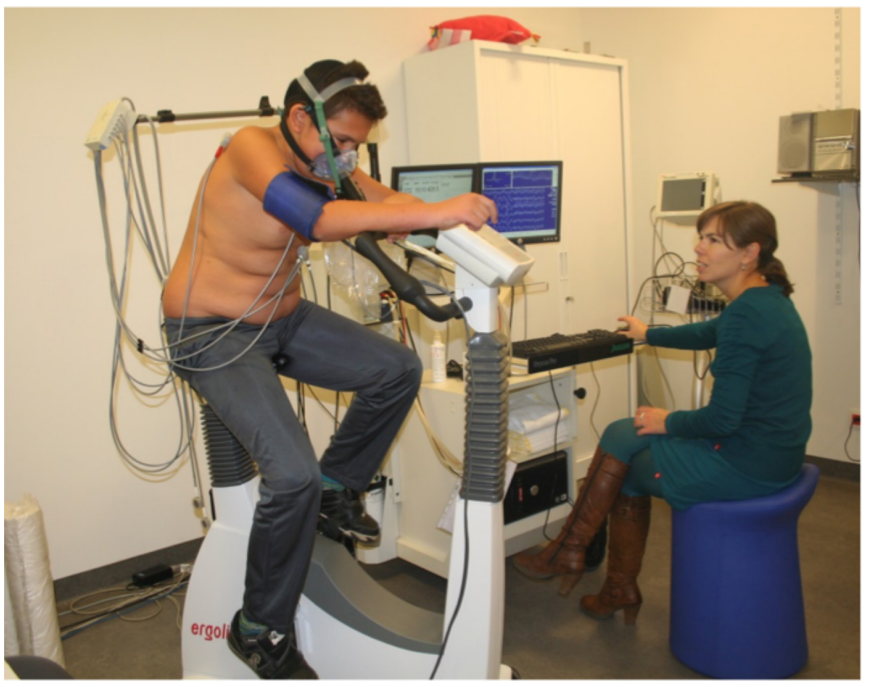

Figure 1 Bicycle Ergometer Exercise Test (stock photograph reproduced with permission from UZ Gent).

the statistical analyses, means of the echocardiographic parameters derived from three cardiac cycles were used.

\section{Bicycle ergometer exercise test}

After the isometric test all study participants underwent a dynamic maximal stress test on a fully automated ergospirometry system with integrated 12-lead ECG and cyclo-ergometer (Ergoline Ergoselect 100K, Bitz, Germany). Ramp protocol was used: at start, workload was set at $0 \mathrm{~W}$, and during the exercise, workload increased ramp wise with $0.25 \mathrm{~W} / \mathrm{kg}$ in a linear way. Participants cycled at constant speed of 60 rotations per minute $(\mathrm{rpm})$ and were verbally encouraged to achieve maximum effort.(figure 1) The exercise was terminated when the patient reached its self-determined point of full exhaustion or was unable to maintain a cycling frequency of $60 \mathrm{rpm}$. This was followed by a recovery period of $6 \mathrm{~min}$.

HR was calculated from the 12-lead ECG (Marquette, GE Healthcare, UK). Blood pressure was obtained every 3 min during exercise and every 2 min during recovery by using an integrated blood pressure device (Tango, SunTech Medical, USA). During the test, breath-bybreath analysis of expiratory gases was performed with a metabolic measuring system (Oxycon Pro, Jaeger, CareFusion Corporation, vs) in order to retrieve respiratory data to define peak VO2.

\section{Statistical analysis}

Data were statistically analysed with SPSS V.25. The values of both stress tests were compared between the coarctation cohort and controls. Included in the analysis were clinical data (age, sex, BMI and age at repair) and echocardiographic indexes. Results, unless stated otherwise, are expressed as mean $\pm \mathrm{SD}$. The normality Shapiro-Wilk test with visual support of histograms was performed to determine whether continuous variables were normally distributed. If so, the differences between groups were evaluated by unpaired Student's t-test. Otherwise, data were compared using the Mann-Whitney $\mathrm{U}$ test. The $\chi^{2}$ test was used to compare categorical variables between groups. The variables of the same cohort were evaluated using the paired Student t-test or the Wilcoxon signedranks test. The relation between variables was assessed by determination of the Pearson or Spearman coefficient. A probability value of $\mathrm{p}<0.05$ was considered to be statistically significant.

\section{RESULTS \\ Clinical data}

In the coarctation cohort 5 female and 14 male patients, mean age 13.0 years, were included. No significant differences were observed between patients and controls with respect to sex, age, weight and length. However, the ratio girls/boys was higher in the control cohort, although this did not reach statistical significance $(p=0.23)$. Aortic repair had been performed at a median age of 1.5 months $(0.1-47.7)$, with $78 \%$ of the subjects undergoing surgery within the first 6 months of life. Forty-two per cent of the included patients had a BAV and $47 \%$ had a hypoplastic arch. Clinical characteristics of the study group are given in table 1.

\section{Blood pressure and HR data}

The systolic blood pressure (SBP), diastolic blood pressure (DBP) and HR before (baseline), during (exercise) and immediately after (recovery) the stress tests are shown in table 2.

There were no differences in resting $\mathrm{BP}$ or $\mathrm{HR}$ before the isometric handgrip test or before the bicycle ergometry.

When performing bicycle ergometry, the SBP and DBP increased with, respectively, 33\% and 3\% in coarctation patients. There was no difference in SBP (baseline, exercise, recovery and $\Delta$ ) between the coarctation and the control group. The peak DBP and $\triangle \mathrm{DBP}$ were significantly lower in coarctation patients compared with controls $(\mathrm{p}<0.05)$, because DBP remained unchanged in patients with repaired coarctation $(2 \pm 14 \mathrm{~mm} \mathrm{Hg})$, wheras in increased with $13 \pm 14 \mathrm{~mm} \mathrm{Hg}$ in the controls. HR almost doubled in both cohorts, although the coarctation group achieved a statistically $11 \mathrm{bpm}$ lower maximal HR than controls $(\mathrm{p}<0.05)$.

During isometric handgrip, SBP and DBP increased with, respectively, $16 \%$ and $25 \%$, without a significant differences in response between the coarctation patients and the control group. During handgrip test HR increased in coarctation patients and in controls with, respectively, $16 \%$ and $31 \%$. As was the case during bicycle ergometry, the degree of increase in HR test was significantly higher in controls compared with the coarctation cohort $(\mathrm{p}<0.05)$.

When comparing the adynamic responses during bicycle ergometry and isometric handgrip, as expected, the maximum SBP and HR responses were, respectively, $21.2 \%$ and $101 \%$ higher during bicycle ergometry (both 


\begin{tabular}{lll}
\hline Table 1 & Basic clinical data & \\
\hline \multicolumn{4}{c}{ CoA } & Controls \\
\hline No. & 19 & 20 \\
\hline Sex $9-{ }^{-}$ & $5-14$ & $9-11$ \\
\hline Mean age (years) & $13.0 \pm 2.3$ & $12.7 \pm 2.1$ \\
Weight $(\mathrm{kg})$ & $47.9 \pm 17.3$ & $44.5 \pm 13.0$ \\
Length $(\mathrm{cm})$ & $155 \pm 13$ & $156 \pm 15$ \\
\hline BMl $\left(\mathrm{kg} / \mathrm{m}^{2}\right)$ & $19.4 \pm 4.6$ & $17.9 \pm 2.5$ \\
\hline BSA (m $\left.{ }^{2}\right)$ & $1.4 \pm 0.3$ & $1.4 \pm 0.3$ \\
Age at operation (mo, median) & $1.5(0.1-47.7)$ \\
\hline Bicuspid valve & 8 & \\
Hypoplastic arch & 9 & \\
\hline
\end{tabular}

Data are expressed as mean $\pm \mathrm{SD}$; median (minimum, maximum). $\mathrm{BMI}$, body mass index; BSA, body surface area; CoA, coarctation of the aorta.

$\mathrm{p}<0.01)$. The SBP was also significantly higher during recovery when performing bicycle ergometry $(\mathrm{p}<0.01)$. In contrast, as DBP increased significantly during handgrip, but not during bicycle ergometry, DBP was significantly higher when executing the isometric handgrip test $(\mathrm{p}=0.001)$.

\section{Echocardiographic data}

The echocardiographic measurements of LV mass and function were compared between the coarctation cohort and controls and are summarised in table 2 and in figure 2.

There were no significant differences in LV dimensions or LV mass between the study groups.

The diastolic function of CoA patients was significantly different from controls: they had significantly higher transmitral $\mathrm{E}$ and $\mathrm{A}$ velocities and significantly lower tissue doppler $\mathrm{E}^{\prime}$ and $\mathrm{A}^{\prime}$ velocities. During exercise, in coarctation patients, the $\mathrm{E}$ wave velocity decreased by $3.6 \%(p=0.21)$ and the A wave increased by $20.5 \%$ $(\mathrm{p}<0.05)$ resulting in an $\mathrm{E} / \mathrm{A}$ ratio decrease of with $26.3 \%$ during exercise $(p<0.05)$. The increase of the A wave can be explained by the importance of atrial contraction during exercise. These effects were mirrored in the tissue Doppler data with a decrease of the $\mathrm{E}^{\prime}$ wave by $4.7 \%$ $(\mathrm{p}=0.13)$, an increase of the $\mathrm{A}^{\prime}$ wave with $33.1 \%(\mathrm{p}<0.01)$ during handgrip exercise.

The $\mathrm{E} / \mathrm{E}^{\prime}$ ratio, a marker of diastolic filling pressure was higher in CoA than controls, although this difference only reached statistical significance during handgrip exercise. Except for the latter, there were no big differences in haemodynamic response during handgrip between CoA and controls.

Conventional parameters of systolic function (fractional shortening (FS) and ejection fraction (EF)) were similar between CoA and controls, at rest and during handgrip. The more sensitive tissue Doppler $\mathrm{S}^{\prime}$ was however significantly lower already at rest in CoA subjects $(5.1 \pm 1.5 \mathrm{~cm} / \mathrm{s}$ vs $6.5 \pm 1.1 \mathrm{~cm} / \mathrm{s}$ ). This difference at rest enlarged further during handgrip as the $\mathrm{S}^{\prime}$ amplitude decreased by $5 \%$ in the CoA group (NS) while remaining unchanged in the controls.

No demonstrable differences were found in stroke volume (SV) and EF when performing isometric exercise (insignificant increase with $0.6 \%$ ). Due to the increase in $\mathrm{HR}$, cardiac output (CO) was significantly increased with $19.6 \%(\mathrm{p}<0.01)$. Interestingly, stroke volume (indexed for body surface area) decreased in controls but remained unchanged in CoA subjects $(\Delta S V I ; p=0.043)$. Because of the larger HR increase in controls, no differences were found in $\mathrm{CO}$ among the study groups.

\section{Exercise capacity}

Oxygen consumption at maximal exercise is considered to be the gold standard parameter to assess exercise capacity.

When performing bicycle ergometry, VO2max was lower in CoA patients $(36.2( \pm 11.8 \mathrm{~mL} / \mathrm{min} / \mathrm{kg})$ compared with controls $(45.7( \pm 6.1 \mathrm{~mL} / \mathrm{min} / \mathrm{kg} ; \mathrm{p}<0.01)$.

\section{BMI and V02 max}

Explorative analyses suggested that the relation between BMI and VO2 max might be different in the control group compared with the coarctation group. To be able to compare the subjects, we used the BMI charts developed for Flemish children to determine the BMI percentile for age and sex. ${ }^{26}$ In figure 3 , we see that VO2max correlates negatively with increasing BMI percentiles in both groups. Although the decrease in VO2max with increasing BMI seems more pronounced in the coarctation group, this did not reach statistical significance in our small sample.

\section{DISCUSSION}

The present research is to the best of our knowledge the first time that isometric exercise in conjunction with echocardiographic examination is used in children with repaired coarctation.

Our main findings are that in patients with repaired CoA diastolic function and systolic function (the latter only when measured using more sensitive tissue Doppler methods) are decreased compared with controls. These relative differences were not strongly influenced when remeasured at a higher operating pressure (during isometric handgrip). Although during handgrip in coarctation subjects $\mathrm{E} / \mathrm{E}^{\prime}$, a marker of elevated LV filling pressures became significantly higher than in controls and $S^{\prime}$ tended (non-significantly) to decrease further while remaining unchanged in control subjects.

Our conventional measures of systolic function (EF and $\mathrm{SF}$ ) were similar in CoA compared with controls. Despite the fact that some studies found an increased systolic function, the absolute values of these variables corresponded to those in this study. ${ }^{14-27}$ However, the conclusion that LV systolic function is usually preserved in patients with repaired coarctation without stenosis 
Table 2 Echocardiographic data

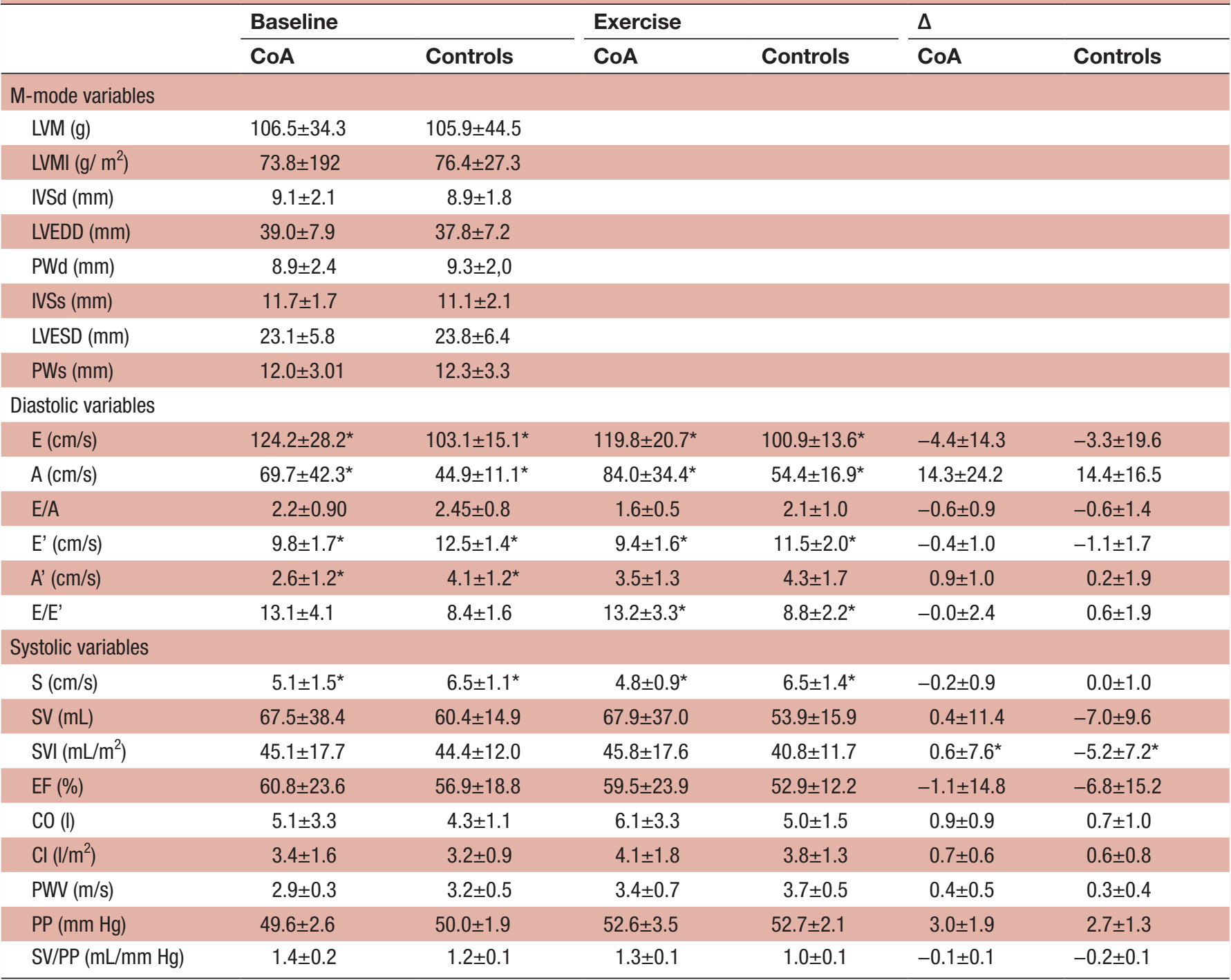

Data are expressed as mean $( \pm \mathrm{SD})$. It was verified whether the difference between CoA and controls was significant $\left({ }^{*} \mathrm{p}<0.05\right)$.

$\mathrm{Cl}$, Cardiac Index; CO, Cardiac Output; CoA, coarctation of the aorta; EF, Ejection Fraction; IVSd, Interventricular Septum diastolic; IVSs, Interventricular Septum systolic; LVEDD, Left Ventricular End-Diastolic Diameter; LVM, Left Ventricular Mass; LVMI, Left Ventricular Mass Index; PP, Pulse Pressure; PWd, Posterio Wall diastolic; PWs, Poster Wall systolic; PWV, Pressure Wave Velocity; SV, Stroke Volume; SVI, Stroke Volume Index; SV/PP, Stoke Volume/Pulse Pressure.

might need revisiting in the light of the decreased $S^{\prime}$ we observed. In many disease conditions (such as hypertrophic cardiomyopathy), a decrease in $\mathrm{S}^{\prime}$ is a sensitive and early marker of declining systolic function, preceding a decrease in $\mathrm{EF}^{30}$

In our data, children with CoA repair at young age show abnormalities of the LV diastolic function at rest and during exercise. Compared with controls, they have significantly higher $\mathrm{E}$ and $\mathrm{A}$ waves and reduced $\mathrm{E} / \mathrm{A}$ ratio, indicating a greater dependence on atrial contraction in coarctation patients. Present at rest, there was no further deterioration during isometric exercise, although the $\mathrm{E} / \mathrm{E}^{\prime}$ ratio, an approximation of the $\mathrm{LV}$ filling pressure, became significantly increased in coarctation patients. Generally our findings (at rest) are in agreement with various studies. ${ }^{13} 31$
As in other studies, no significant differences were found in resting blood pressure and HR between coarctation patients and controls. ${ }^{13} 1632$ The responses in SBP during isometric $\mathrm{HG}$ and bicycle ergometry was similar in both groups. In contrast, maximal HRs (in both exercises) and peak DBP and change in DBP were significantly lower in coarctation patients compared with controls during isometric handgrip but not during bicycle ergometry. The response to an isometric stress test differs in children compared with adults, and the increase of HR in children surpasses the very subtle increase in HR in adults when executing the isometric handgrip test ${ }^{33}$ (E Rietzschel, personal data, 2019, using a similar protocol in $>2000$ healthy volunteers aged 56 years on average, HR increased only slightly by $7 \pm 5$ beats/min; unpublished data; manuscript in preparation). 

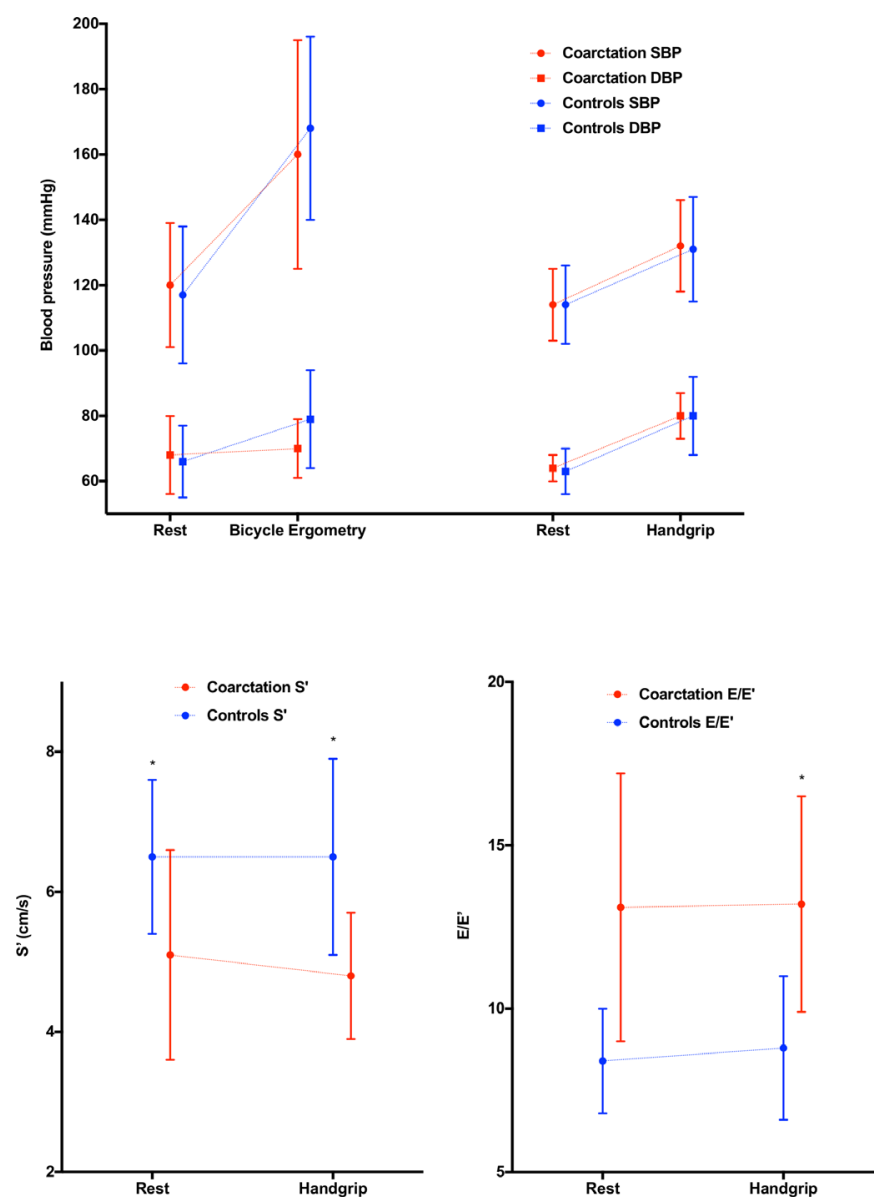

Figure 2 BMI percentile and VO2/kg ( $\mathrm{ml} / \mathrm{min} / \mathrm{kg})$ compared in RCoA patients and controls.

The increase in SBP and HR were much higher during bicycle ergometry than during handgrip. The first is a dynamic stress test of maximal effort with increases in $\mathrm{CO}$ giving volume load on the $\mathrm{LV}$, while the latter is a submaximal static contraction against resistance resulting in an increased pressure load on the $\mathrm{LV} .^{22}$

Functionally, as in other studies, exercise capacity as assessed by VO2max was clearly lower in CoA patients compared with controls. ${ }^{20}{ }^{34}$ This is consistent with the lower peak HR found in patients with repaired coarctation. Since isometric handgrip is a submaximal stress

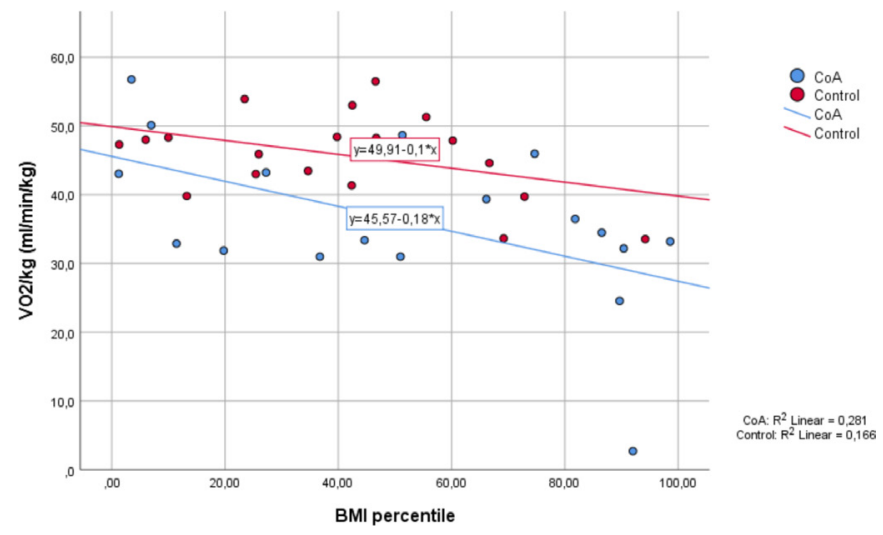

Figure 3 Bicycle exercise test with ergospirometry. test, no conclusions in terms of exercise capacity can be reached when performing this stress test. The lower VO2max seemed more pronounced with increasing BMI percentiles in the coarctation group, although this needs to be confirmed in a larger cohort as this did not reach statistical significance on our small sample.

In our study, no increase in LV dimensions or LV mass was observed in CoA patients. In contrast, several studies have shown an increased LVM in patients with repaired coarctation. ${ }^{12131528} 2932$ In comparison with these investigations, our patients were younger and underwent surgical repair at lower age. This potentially suggests that early repair reduces the risk of an increased LVM in coarctation patients. Tantengco et $a l^{15}$ demonstrated a positive correlation between LVMI and hypertension in patients with repaired coarctation. Nevertheless, it has been shown that an increase of LVM occurs even in normotensive patients with repaired coarctation. ${ }^{12}{ }^{28} \mathrm{LV}$ hypertrophy is an independent risk factor for cardiovascular morbidity and mortality. ${ }^{28}$

Patients with repaired CoA remain at higher risk of developing cardiovascular complications. ${ }^{39} 12$ Currently, follow-up includes blood pressure measurements and echocardiography at rest, completed with bicycle ergometry. ${ }^{10}$ Exercise testing plays an essential role because haemodynamic parameters may be normal at rest but changes may appear first during exercise. ${ }^{5} 1924$ Exercise-induced hypertension is assumed to be a predictor of arterial hypertension. ${ }^{12} 1935$ Even without hypertension, abnormal diastolic and systolic LV function can be found in patients with repaired coarctation. ${ }^{27} 2831$ This suggests that LV dysfunction appears before patients become hypertensive. ${ }^{35}$ To detect LV dysfunction, echocardiography was used. Images of good quality are easy to obtain during isometric stress testing but next to impossible during bicycle ergometry. ${ }^{24}$ In cardiovascular disorders with increased afterload, like CoA, isometric handgrip test could be interesting in unmasking latent LV dysfunction.

Evaluating the cardiac response to an increased pressure load is useful to estimate the cardiac reserve..$^{22} 36$

Although in our study the peak SBP was similar to controls, many previous studies reported higher peak SBP. ${ }^{19} 203437$ This discrepancy can be explained by differences in study populations, where often the age at repair was much higher. Furthermore, when studying coarctation patients after puberty, the influence of hormones should be taken into account, in addition to the genetic and haemodynamic factors. ${ }^{12}$

\section{Strengths and weaknesses}

Comparison of our haemodynamic responses during isometric handgrip with other studies was not possible since this is the first study that reports the influence of isometric exercise in children with repaired coarctation. The major limitation of this study relates to the number of patients studied. This relatively small patient cohort has limited the statistical power to identify risk factors. 
Nonetheless, this study has provided new insights on the LV function in this population and should be seen more as a proof of concept and feasibility testing. Another shortcoming is the possibility that patients perform a Valsalva manoeuvre during isometric handgrip. This could be avoided by carefully observing and instructing the patient during exercise (and by engaging the in conversation). Another limitation is the fact that simultaneous blood pressure measurements were not performed in the arm and legs during exercise. This could have given additional information about a change in gradient across the repaired coarctation during exercise.

We believe that isometric exercise in conjunction with echocardiography could be useful in children with repaired coarctation. The fact that no further deterioration in diastolic function was found in this study during exercise could possibly be related to early good repair. This does not preclude the possibility that diastolic function could show significant changes during exercise in other patients where repair was at later age or other possible factors are present, like recoarctation. Therefore, the potential usefulness use of isometric handgrip test should be further investigated in the follow-up of patients with repaired coarctation.

\section{CONCLUSIONS}

We showed for the first time that echocardiography is feasible in children with repaired coarctation during isometric stress testing.

Both diastolic function and systolic function are significantly decreased compared with controls.

Further studies in adults (who have had a longer period since repair of coarctation) or in children with later repair might show more pronounced changes from controls.

The long-term clinical impact (if any) of the subtle systolic and diastolic dysfunction we documented remains to be elucidated.

\section{Highlights}

- Submaximal isometric handgrip test (HG) is feasible and easy in children aged 9-15 years.

- Childen after coarctation repair have impaired systolic and diastolic function

- There is a tendency for the impaired systolic and diastolic dysfunction to deteriorate further during HG test.

Contributors All authors contributed to this manuscript in all four categories: substantial contributions to the conception or design of the work; or the acquisition, analysis or interpretation of data for the work; drafting the work or revising it critically for important intellectual content; final approval of the version to be published; and agreement to be accountable for all aspects of the work in ensuring that questions related to the accuracy or integrity of any part of the work are appropriately investigated and resolved.

Funding The authors have not declared a specific grant for this research from any funding agency in the public, commercial or not-for-profit sectors.

Competing interests None declared.

Patient consent for publication Not required.
Ethics approval Ethics Board UZ Gent Belgian Registry Number: B670201214536. This investigation was reviewed and approved by the ethical committee of Ghent University Hospital (protocol number: B670201214886).

Provenance and peer review Not commissioned; externally peer reviewed. Data availability statement Data are available on reasonable request.

Open access This is an open access article distributed in accordance with the Creative Commons Attribution Non Commercial (CC BY-NC 4.0) license, which permits others to distribute, remix, adapt, build upon this work non-commercially, and license their derivative works on different terms, provided the original work is properly cited, appropriate credit is given, any changes made indicated, and the use is non-commercial. See: http://creativecommons.org/licenses/by-nc/4.0/.

ORCID iD

Joseph Panzer http://orcid.org/0000-0002-8667-8001

\section{REFERENCES}

1. Vriend JWJ, Mulder BJM. Late complications in patients after repair of aortic coarctation: implications for management. Int J Cardiol 2005;101:399-406.

2. Jay G, On J, Arnold C, et al. Pediatric surgery. Mosby Inc: Maryland Heights (MO), 2006.

3. Robert B, Douglas M, Douglas Z, et al. Braunwald's heart disease. 9th ed. Philadelphia, PA: Saunders, 2012.

4. Bambul Heck P, Pabst von Ohain J, Kaemmerer H, et al. Survival and cardiovascular events after coarctation-repair in long-term follow-up (COAFU): predictive value of clinical variables. Int $J$ Cardiol 2017;228:347-51.

5. Instebø A, Norgård G, Helgheim V, et al. Exercise capacity in young adults with hypertension and systolic blood pressure difference between right arm and leg after repair of coarctation of the aorta. Eur J Appl Physiol 2004;93:116-23.

6. De Mey S, Segers P, Coomans I, et al. Limitations of Doppler echocardiography for the post-operative evaluation of aortic coarctation. J Biomech 2001;34:951-60.

7. Leonard L. Pathophysiology of heart disease. Philadelphia, PA: Lippincott Williams \& Wilkins, 2011.

8. de Divitiis M, Pilla C, Kattenhorn M, et al. Vascular dysfunction after repair of coarctation of the aorta: impact of early surgery. Circulation 2001;104(12 Suppl 1):I165-70.

9. Hager A, Kanz S, Kaemmerer $\mathrm{H}$, et al. Coarctation long-term assessment (Coala): significance of arterial hypertension in a cohort of 404 patients up to 27 years after surgical repair of isolated coarctation of the aorta, even in the absence of restenosis and prosthetic material. J Thorac Cardiovasc Surg 2007;134:738-45.

10. Celermajer DS, Greaves K. Survivors of coarctation repair: fixed but not cured. Heart 2002;88:113-4.

11. Toro-Salazar OH, Steinberger J, Thomas W, et al. Long-Term followup of patients after coarctation of the aorta repair. Am J Cardiol 2002;89:541-7.

12. Luijendijk P, Bouma BJ, Vriend JWJ, et al. Usefulness of exerciseinduced hypertension as predictor of chronic hypertension in adults after operative therapy for aortic isthmic coarctation in childhood. Am J Cardiol 2011;108:435-9.

13. di Salvo G, Pacileo G, Limongelli G, et al. Abnormal regional myocardial deformation properties and increased aortic stiffness in normotensive patients with aortic coarctation despite successful correction: an ABPM, standard echocardiography and strain rate imaging study. Clin Sci 2007;113:259-66.

14. Krieger EV, Clair M, Opotowsky AR, et al. Correlation of exercise response in repaired coarctation of the aorta to left ventricular mass and geometry. Am J Cardiol 2013;111:406-11.

15. Tantengco MV, Ross RD, Humes RA, et al. Enhanced resting left ventricular filling in patients with successful coarctation repair and exercise-induced hypertension. Am Heart J 1997;134:1082-8.

16. Gardiner HM, Celermajer DS, Sorensen KE, et al. Arterial reactivity is significantly impaired in normotensive young adults after successful repair of aortic coarctation in childhood. Circulation 1994;89:1745-50.

17. Swan L, Ashrafian H, Gatzoulis MA. Repair of coarctation: a higher goal? Lancet 2002;359:977-8.

18. Swan Let al. Exercise systolic blood pressures are of questionable value in the assessment of the adult with a previous coarctation repair. Heart 2003;89:189-92.

19. Buys R, Van De Bruaene A, Müller J, et al. Usefulness of cardiopulmonary exercise testing to predict the development of arterial hypertension in adult patients with repaired isolated coarctation of the aorta. Int J Cardiol 2013;168:2037-41. 
20. Hager A, Kanz S, Kaemmerer H, et al. Exercise capacity and exercise hypertension after surgical repair of isolated aortic coarctation. $A m \mathrm{~J}$ Cardiol 2008;101:1777-80.

21. Cifra B, Dragulescu A, Border WL, et al. Stress echocardiography in paediatric cardiology. Eur Heart $J$ Cardiovasc Imaging 2015;16:1051-9.

22. Victor F, Jonathan M. Manual of exercise testing. Maryland Heights (MO): Mosby Inc, 2007.

23. Bezucha GR, Lenser MC, Hanson PG, et al. Comparison of hemodynamic responses to static and dynamic exercise. J Appl Physiol Respir Environ Exerc Physiol 1982;53:1589-93.

24. Bryhn M, Castenfors J. Left ventricular diastolic and systolic function during isometric exercise: an echocardiographic study. Clin Cardiol 1987;10:71-7.

25. Laird WP, Fixler DE, Huffines FD. Cardiovascular response to isometric exercise in normal adolescents. Circulation 1979;59:651-4.

26. Roelants M, Hauspie R, Hoppenbrouwers K. References for growth and pubertal development from birth to 21 years in Flanders, Belgium. laboratory of Anthropogenetics, Vrije Universiteit Brussel (VUB), Belgium, and department of youth health care. Belgium Katholieke Universiteit Leuven; 2009.

27. Krogmann ON, Rammos S, Jakob M, et al. Left ventricular diastolic dysfunction late after coarctation repair in childhood: influence of left ventricular hypertrophy. J Am Coll Cardiol 1993;21:1454-60.

28. Ong CM, Canter CE, Gutierrez FR, et al. Increased stiffness and persistent narrowing of the aorta after successful repair of coarctation of the aorta: relationship to left ventricular mass and blood pressure at rest and with exercise. Am Heart $J$ 1992;123:1594-600.
29. Moskowitz WB, Schieken RM, Mosteller M, et al. Altered systolic and diastolic function in children after "successful" repair of coarctation of the aorta. Am Heart J 1990;120:103-9.

30. Butz T, van Buuren F, Mellwig K-P, et al. [Echocardiographic tissue Doppler imaging analysis of the systolic and early diastolic velocities of the mitral annulus motion in hypertrophic cardiomyopathy and in top-level athletes]. Ultraschall Med 2012;33:455-62.

31. Lombardi KC, Northrup V, McNamara RL, et al. Aortic stiffness and left ventricular diastolic function in children following early repair of aortic coarctation. Am J Cardiol 2013;112:1828-33.

32. Leandro J, Smallhorn JF, Benson L, et al. Ambulatory blood pressure monitoring and left ventricular mass and function after successful surgical repair of coarctation of the aorta. J Am Coll Cardiol 1992;20:197-204.

33. Rietzschel E-R, De Buyzere ML, Bekaert S, et al. Rationale, design, methods and baseline characteristics of the Asklepios study. Eur $J$ Cardiovasc Prev Rehabil 2007:14:179-91.

34. Rhodes J, Geggel RL, Marx GR, et al. Excessive anaerobic metabolism during exercise after repair of aortic coarctation. $J$ Pediatr 1997;131:210-4.

35. O'Sullivan J. Late hypertension in patients with repaired aortic coarctation. Curr Hypertens Rep 2014;16:421.

36. Hietanen E. Cardiovascular responses to static exercise. Scand $J$ Work Environ Health 1984:10:397-402.

37. Guenthard J, Wyler F. Exercise-Induced hypertension in the arms due to impaired arterial reactivity after successful coarctation resection. Am J Cardiol 1995;75:814-7. 